\title{
Current therapeutic strategies of heterotopic ossification - a survey amongst orthopaedic and trauma departments in Germany
}

Sebastian Winkler, ${ }^{*}$ Ferdinand Wagner, Markus Weber, Jan Matussek, Benjamin Craiovan, Guido Heers, Hans Robert Springorum, Joachim Grifka and Tobias Renkawitz

\begin{abstract}
Background: Heterotopic ossification $(\mathrm{HO})$ is a complication after tissue trauma, fracture and surgery (i.e. total hip arthroplasty). Prophylaxis is the most effective therapy. If $\mathrm{HO}$ formations become symptomatic and limit patients' quality of life, revision surgery is indicated and is usually combined with a perioperative oral prophylaxis (NSAIDs) and/or irradiation. However, a long-term use of NSAIDs can induce gastro-intestinal or cardiac side-effects and possible bony non-unions during fracture healing. Subject of this study was to assess the current status of $\mathrm{HO}$ prophylaxis after injuries or fractures and to evaluate current indications and strategies for excision of symptomatic $\mathrm{HO}$.
\end{abstract}

Methods: Between 2013 and 2014, a questionnaire was sent to 119 orthopaedic and trauma surgery departments in Germany. Participation was voluntary and all acquired data was given anonymously.

Results: The cumulative feedback rate was $71 \%$. Trauma and orthopaedic surgery departments in Germany recommend oral $\mathrm{HO}$ prophylaxis after acetabulum and femoral neck fractures, elbow dislocation, and fracture or dislocation of the radial head. Pain upon movement and an increasing loss of range of motion in the affected joint are considered to be clear indications for $\mathrm{HO}$ surgery. A partial removal of ROM-limiting $\mathrm{HO}$ formations was also considered important. The vast majority of all departments include perioperative oral $\mathrm{HO}$ prophylaxis and/or irradiation if surgical HO removal is planned. The choice and duration of NSAIDs is highly variable.

Conclusion: $\mathrm{HO}$ is of clinical significance in current traumatology and orthopaedics. Certain fractures and injuries are prone to $\mathrm{HO}$, and prophylactic measures should be taken. The respondents in this survey assessed current therapeutic strategies for $\mathrm{HO}$ formations similarly. These concepts are in line with the literature. However, the duration of perioperative oral $\mathrm{HO}$ prophylaxis varied greatly among the specialist centres. This is significant as a long-term use of NSAIDs fosters a potential risk for the patients' safety and could influence the clinical outcome. National and international guidelines need to be developed to further reduce $\mathrm{HO}$ rates and improve patients' safety in trauma and orthopaedic surgery.

Keywords: Heterotopic ossification, Trauma, Therapy, Fracture, Prophylaxis

\footnotetext{
* Correspondence: sebastianwinkler@email.de

Department of Orthopaedic Surgery, Regensburg University Medical Centre,

Kaiser-Karl-V-Allee 3, 93077 Bad Abbach, Germany
} 


\section{Background}

Heterotopic ossification ( $\mathrm{HO})$ can occur after tissue trauma (i.e. gunshot wounds), cerebral and spinal cord injury, bone fractures or surgery such as total hip arthroplasty (THA) [1, 2]. The pathogenesis of $\mathrm{HO}$ is not fully understood.

An effective $\mathrm{HO}$ prophylaxis requires identifying known risk factors in the patient, using gentle surgical techniques and applying perioperative non-steroidal anti rheumatic drugs (NSAIDs), COX-2 blockers and lowdose irradiation [2]. This is well established for THA. Little is known about the significance of $\mathrm{HO}$ prophylaxis in blunt extremity trauma and fracture treatment. Nevertheless, some studies have suggested that NSAIDs, which suppress inflammatory prostaglandins during initial tissue inflammation, could cause delayed fracture healing in animals $[3,4]$. Large and symptomatic $\mathrm{HO}$ formations can only be treated surgically [5]. However, revision surgery itself can induce a $\mathrm{HO}$ relapse.

Historically, Germany had a separation of trauma and orthopaedic surgery departments. Consequently, different therapy strategies evolved in both fields. Several years ago this separation was, however, revoked and a single residency program was created. Nonetheless, differences still remain in both disciplines.

The intention of this study was to investigate the following questions:

1. Is HO clinically relevant?

2. Are HO-prone injuries assessed in a similar manner in different specialist centres?

3. Are there standard $\mathrm{HO}$ prophylactic measures after fractures and tissue trauma?

4. What are the current indications and strategies for surgical $\mathrm{HO}$ removal if $\mathrm{HO}$ formations limit patients' quality of life?

\section{Methods}

After a current literature review, the authors developed a questionnaire. The 17 questions aimed to assess prophylactic and therapeutic strategies for heterotopic ossification in orthopaedic and trauma surgery. Indications for surgery and surgical techniques were graded on a 4-point scale (insignificant, of little importance, important or very important).

The study was carried out from 2013 to 2014 in 34 orthopaedic and 30 trauma surgery departments in German university hospitals. When there were separate departments in the same hospital, both departments were addressed. Furthermore, we contacted 55 German hospitals that had been granted a certificate (EndoCert ${ }^{\circ}$ ) for high standards in THA from the German Association of Orthopaedic Surgery and were listed on the official homepage until January 9th 2014. The study participants were trained orthopaedic/trauma surgeons, not patients. The respondents agreed to participate voluntarily in this trial by sending back the completed questionnaire in an anonymous fashion. Therefore, an informed consent was waived. The collected data included estimations, therapy assessments or ratings and did not allow any conclusion about the participants' identity. An approval by the local IRB was waived according to the guideline for Good Clinical Practice and the Declaration of Helsinki as this trial did not involve the collection of sensitive data from humans.

\section{Statistical analysis}

Statistics were generated with Microsoft Excel 2008. Statistics used for this study were descriptive only as several answers to the questions included estimations from the questionnaire recipients. Hence, standard parameters such as mean, median, maximum and minimum were detected, but no statistical analysis for significance was performed.

\section{Results}

The total response rate was $71 \%$ (85 of 119). The feedback rate was $76 \%$ (42 of 55) among non-university hospitals, $67 \%$ (20 of 30) in trauma and $68 \%$ (23 of 34) in the orthopaedic departments of university hospitals.

The majority of surgeons offer a regular radiological follow-up that enables a realistic assessment of the course of treatment. Most respondents assessed HOprone injuries in a similar manner and therefore recommend an oral $\mathrm{HO}$ prophylaxis after certain fractures (see Table 1 for details).

The indications for $\mathrm{HO}$ excision were assessed similarly. Pain at rest, pain during joint movement and a reduced range of motion (ROM) are considered important or very important. Thirty-seven percent of the respondents found a skeleton scintigraphy to be useful. The evaluation of surgical strategy and techniques for $\mathrm{HO}$ excision were moderately different among orthopaedic and trauma surgeons (see Table 2 for details).

In $\mathrm{HO}$ excision, the majority of surgeons change their $\mathrm{HO}$ prophylactic strategy by applying irradiation and/or administering a different NSAID. The choice of medication and the amount of time it was taken were inconsistent. Irradiation is usually planned pre-operatively in Germany (see Table 3 for details).

\section{Discussion}

In recent years, strategies for $\mathrm{HO}$ in total hip arthroplasty have been discussed in various studies [6]. A national treatment guideline in Germany (2009) recommends NSAID use for HO prophylaxis after THA and elbow injuries/surgery [7]. No recommendation was given for fractures, tissue trauma and spinal or cerebral injuries. Fracture osteosynthesis and manipulation of soft tissue and joints seem to be 
Table $1 \mathrm{HO}$ prophylaxis in fracture treatment and summary of injuries and fracture types that are prone to HO formation according to respondents; $\mathrm{HO}=$ heterotopic ossification; $\mathrm{AC}=$ acromio-clavicular; $\mathrm{min} .=$ minimum, max. =maximum

\begin{tabular}{|c|c|c|c|c|}
\hline & & Germany & & \\
\hline & University (trauma) & University (orthopaedic) & Non-university hospitals & Total \\
\hline Feed back rate & $67 \%(n=20$ of 30$)$ & $68 \%(n=23$ of 34$)$ & $76 \%(n=42$ of 55$)$ & $71 \%(n=85$ of 119$)$ \\
\hline $\mathrm{HO}$ prophylaxis for risk fractures & $79 \%$ & $67 \%$ & $59 \%$ & $67 \%$ \\
\hline Mean time of prophylaxis (days) & 25 (min. $14-\max .42)$ & $17(\min .7-\max .42)$ & $21(\min .7-\max .84)$ & $21(\min .7-\max .84)$ \\
\hline Regular radiological follow-up & $85 \%$ & $96 \%$ & $67 \%$ & $79 \%$ \\
\hline Injuries and fractures prone to $\mathrm{HC}$ & & & & \\
\hline Acetabulum fracture & $79 \%$ & $52 \%$ & $38 \%$ & $54 \%$ \\
\hline Elbow dislocation & $42 \%$ & $24 \%$ & $31 \%$ & $32 \%$ \\
\hline Radial head dislocation & $16 \%$ & $5 \%$ & $10 \%$ & $10 \%$ \\
\hline Radial head fracture & $21 \%$ & $14 \%$ & $10 \%$ & $14 \%$ \\
\hline Femoral neck fracture & $11 \%$ & $48 \%$ & $31 \%$ & $30 \%$ \\
\hline Femoral shaft fracture & $0 \%$ & $24 \%$ & $17 \%$ & $14 \%$ \\
\hline Clavicula fracture & $0 \%$ & $5 \%$ & $7 \%$ & $4 \%$ \\
\hline$A C$ joint injury & $0 \%$ & $5 \%$ & $7 \%$ & $4 \%$ \\
\hline Other & $0 \%$ & $0 \%$ & $0 \%$ & $0 \%$ \\
\hline
\end{tabular}

$\mathrm{HO}$ risk factors $[8,9]$. Gunshot or blast injuries can also cause HO formations [10].

The aim of this study was to evaluate current prophylactic strategies after injuries and to analyse therapeutic concepts of symptomatic HO. Additionally, we intended to investigate whether data taken from recent literature had found its way into daily trauma and orthopaedic practice. However, this review has certain limitations. Surveys usually cannot provide strong evidence of cause and effect. Future studies could include face to face follow-up visits for patients who were treated for $\mathrm{HO}$, since the subjective error from patients is hard to remove. Secondly, the survey included closed questions, which are generally considered to be of lesser validity than open-ended questions, which were also included. Ultimately, the results of this study are limited by response rate and the subjective estimations from the respondents. The response rate was $71 \%$ (85/119), which is considered high $[11,12]$.

A main finding of this study is that orthopaedic and trauma surgeons alike consider $\mathrm{HO}$ to be clinically relevant after certain fractures and injuries. Nevertheless, there are differences in current $\mathrm{HO}$ prophylaxis. Trauma surgery departments have a higher rate of HO prophylaxis after risk fractures/injuries compared to orthopaedic university departments and non-university EndoCert ${ }^{\odot}$ hospitals. The oral $\mathrm{HO}$ prophylaxis duration was also slightly higher among trauma surgeons, but on average for three weeks post trauma.

The literature provides numerous clinical trials which found that an oral $\mathrm{HO}$ prophylaxis (indomethacin) can reduce the incidence of large $\mathrm{HO}$ formations (Brooker grades 3 and 4) after certain fractures [13]. It must be taken into account that NSAIDs can lead to delayed fracture healing and non-unions in animals [3, 4]. Despite these results, many patients receive NSAIDs for both, postoperative pain and anti-inflammatory ( $\mathrm{HO}$ prophylactic) treatment after trauma. An evidence- based recommendation for the most effective drug and perioperative application time for oral $\mathrm{HO}$ prophylaxis is currently missing from the literature.

The respondents in this study mostly considered acetabular fractures, elbow dislocation, femoral neck and shaft fractures and radial head dislocation or fracture to be most prone to $\mathrm{HO}$. Current literature supports this assessment. A recent retrospective study (2013) found a $47 \%$ incidence of $\mathrm{HO}$ (56 of 120 patients) after surgery for acetabular fracture [14]. After elbow fracture surgery involving the proximal radius and/or ulna, $\mathrm{HO}$ was reported in $37 \%$ of cases (48 of 142) [15]. Johansson et al. analysed femoral neck fracture treatment (THA vs. internal fixation): Seventy-one percent (32 of 45) of hips with THA developed $\mathrm{HO}$ compared to $2.5 \%$ (1 of 39 ) in the internal fixation group [16]. Mechanical ventilation time, indomethacin and incidence of head injuries did not differ between the two groups. Plate osteosynthesis seems to create a higher risk for $\mathrm{HO}$ formation than intramedullary nailing in multiple trauma patients [17]. A possible explanation might be that plate osteosynthesis is often used for intraarticular fracture treatment and could induce higher muscle injuries, whereas intramedullary nailing is mostly used for diaphysal fractures. Another risk factor for $\mathrm{HO}$ formation in multiple trauma patients is brain injury. A higher rate of $\mathrm{HO}$ is found 
Table 2 Indication and techniques for surgical $\mathrm{HO}$ removal; $\mathrm{HO}=$ heterotopic ossification

\begin{tabular}{|c|c|c|c|c|}
\hline \multirow{3}{*}{ Indications for surge } & \multirow[b]{2}{*}{ University (trauma) } & \multicolumn{3}{|l|}{ Germany } \\
\hline & & University (orthopaedic) & Non-university hospitals & Total \\
\hline & & & & \\
\hline \multicolumn{5}{|c|}{ Pain at rest } \\
\hline Insignificant & $10 \%$ & $0 \%$ & $0 \%$ & $3 \%$ \\
\hline Of little importance & $40 \%$ & $17 \%$ & $22 \%$ & $25 \%$ \\
\hline Important & $35 \%$ & $57 \%$ & $67 \%$ & $55 \%$ \\
\hline Very important & $15 \%$ & $26 \%$ & $11 \%$ & $17 \%$ \\
\hline \multicolumn{5}{|c|}{ Pain during joint movement } \\
\hline Insignificant & $0 \%$ & $0 \%$ & $0 \%$ & $0 \%$ \\
\hline Of little importance & $11 \%$ & $0 \%$ & $0 \%$ & $3 \%$ \\
\hline Important & $53 \%$ & $64 \%$ & $69 \%$ & $64 \%$ \\
\hline Very important & $37 \%$ & $36 \%$ & $31 \%$ & $33 \%$ \\
\hline \multicolumn{5}{|c|}{ Reduced ROM of affected joint } \\
\hline Insignificant & $0 \%$ & $0 \%$ & $0 \%$ & $0 \%$ \\
\hline Of little importance & $5 \%$ & $9 \%$ & $3 \%$ & $5 \%$ \\
\hline Important & $20 \%$ & $43 \%$ & $56 \%$ & $43 \%$ \\
\hline Very important & $75 \%$ & $48 \%$ & $41 \%$ & $52 \%$ \\
\hline \multicolumn{5}{|c|}{ Increase of $\mathrm{HO}$ formation } \\
\hline Insignificant & $16 \%$ & $13 \%$ & $14 \%$ & $14 \%$ \\
\hline Of little importance & $26 \%$ & $39 \%$ & $36 \%$ & $34 \%$ \\
\hline Important & $42 \%$ & $44 \%$ & $28 \%$ & $37 \%$ \\
\hline Very important & $16 \%$ & $4 \%$ & $22 \%$ & $14 \%$ \\
\hline \multicolumn{5}{|c|}{ Active $\mathrm{HO}$ formation in scintigraphy } \\
\hline Insignificant & $21 \%$ & $4 \%$ & $14 \%$ & $13 \%$ \\
\hline Of little importance & $63 \%$ & $61 \%$ & $39 \%$ & $50 \%$ \\
\hline Important & $16 \%$ & $26 \%$ & $33 \%$ & $28 \%$ \\
\hline Very important & $0 \%$ & $9 \%$ & $14 \%$ & $9 \%$ \\
\hline \multicolumn{5}{|c|}{ Techniques of surgical excision } \\
\hline \multicolumn{5}{|c|}{ Complete excision of $\mathrm{HO}$ formation } \\
\hline Insignificant & $5 \%$ & $0 \%$ & $3 \%$ & $3 \%$ \\
\hline Of little importance & $40 \%$ & $36 \%$ & $30 \%$ & $34 \%$ \\
\hline Important & $45 \%$ & $55 \%$ & $53 \%$ & $51 \%$ \\
\hline Very important & $10 \%$ & $9 \%$ & $14 \%$ & $12 \%$ \\
\hline \multicolumn{5}{|c|}{ Excision of ROM-limiting $\mathrm{HO}$} \\
\hline Insignificant & $5 \%$ & $0 \%$ & $2 \%$ & $3 \%$ \\
\hline Of little importance & $15 \%$ & $30 \%$ & $23 \%$ & $22 \%$ \\
\hline Important & $30 \%$ & $48 \%$ & $46 \%$ & $43 \%$ \\
\hline Very important & $50 \%$ & $22 \%$ & $29 \%$ & $32 \%$ \\
\hline \multicolumn{5}{|c|}{ Tissue interposition after HO removal } \\
\hline Insignificant & $45 \%$ & $13 \%$ & $25 \%$ & $27 \%$ \\
\hline Of little importance & $40 \%$ & $70 \%$ & $61 \%$ & $60 \%$ \\
\hline Important & $10 \%$ & $17 \%$ & $14 \%$ & $13 \%$ \\
\hline Very important & $5 \%$ & $0 \%$ & $0 \%$ & $0 \%$ \\
\hline
\end{tabular}


Table 3 Perioperative irradiation and oral $\mathrm{HO}$ prophylaxis; $\mathrm{HO}=$ heterotopic ossification; Gy = Gray

\begin{tabular}{|c|c|c|c|c|}
\hline & & Germany & & \\
\hline & University (trauma) & University (orthopaedic) & Non-university hospitals & Total \\
\hline Postoperative oral HO prophylaxis & $100 \%$ & $81 \%$ & $86 \%$ & $88 \%$ \\
\hline Perioperative irradiation & $90 \%$ & $96 \%$ & $91 \%$ & $92 \%$ \\
\hline Change in prophylaxis strategy & $65 \%$ & $35 \%$ & $31 \%$ & $38 \%$ \\
\hline Diclofenac & $0 \%$ & $25 \%$ & $30 \%$ & $17 \%$ \\
\hline Median dosage per day & - & $150 \mathrm{mg}$ & $150 \mathrm{mg}$ & $150 \mathrm{mg}$ \\
\hline Ibuprofen & $11 \%$ & $25 \%$ & $10 \%$ & $13 \%$ \\
\hline Median dosage per day & $1800 \mathrm{mg}$ & $1200 \mathrm{mg}$ & $1200 \mathrm{mg}$ & $1600 \mathrm{mg}$ \\
\hline Indomethacin & $89 \%$ & $50 \%$ & $30 \%$ & $57 \%$ \\
\hline Median dosage per day & $150 \mathrm{mg}$ & $150 \mathrm{mg}$ & $100 \mathrm{mg}$ & $100 \mathrm{mg}$ \\
\hline Etoricoxib & $0 \%$ & - & $20 \%$ & $9 \%$ \\
\hline Median dosage per day & - & - & $90 \mathrm{mg}$ & $90 \mathrm{mg}$ \\
\hline Celecoxib & $0 \%$ & - & $10 \%$ & $4 \%$ \\
\hline Median dosage per day & - & - & $400 \mathrm{mg}$ & $400 \mathrm{mg}$ \\
\hline Other & - & & - & $0 \%$ \\
\hline Mean time of oral prophylaxis (days) & $28(\min .14-\max .42)$ & $42(\min .14-\max .98)$ & $21(\min .7-\max .42)$ & $30(\min .7-\max .98)$ \\
\hline Pre-operative irradiation & $75 \%$ & $86 \%$ & $90 \%$ & $83 \%$ \\
\hline Post-operative irradiation & $25 \%$ & $14 \%$ & $10 \%$ & $17 \%$ \\
\hline Times of irradiation & 1 & 1 & 1 & 1 \\
\hline Median dosage in Gy & 7 & 7 & 7 & 7 \\
\hline
\end{tabular}

when serious brain injury occurred and there was a need for mechanical ventilation [18].

If $\mathrm{HO}$ formations increase, they can cause postoperative pain, bony impingement with impaired range of motion of the affected joints, leading ultimately to revision surgery. This survey shows that current indications and strategies for surgical HO removal are similar with trauma and orthopaedic surgeons. Surgical removal of $\mathrm{HO}$ is complicated as the formations are often soft and integrated in the muscle or connective tissue. Some studies demonstrated that excision of $\mathrm{HO}$ can lead to a significantly improved ROM, but pain can often not be minimized [19]. Salazar et al. [20] described a significant, postoperative improvement in ROM after resection of HOs following elbow fractures when preoperative ROM was partially or completely restricted. Consequently surgeons should carefully consider these results from the literature when $\mathrm{HO}$ excision is indicated. At this stage, there is limited data as to whether $\mathrm{HO}$ formations should be removed completely or partially.

If revision surgery is indicated, the vast majority of surgeons combine irradiation and an oral prophylaxis in their therapy regimen. However, this review has found that there are still vast differences in the choice of drug and the perioperative application time (minimum 7 days, maximum 98 days). A majority of trauma surgeons prefer the use of indomethacin in $\mathrm{HO}$ surgery.
An evidence-based recommendation for the most effective $\mathrm{HO}$ prophylaxis (type of drug, application time) following $\mathrm{HO}$ excision is still missing in the current literature. The combination of irradiation and NSAID use for $\mathrm{HO}$ treatment of various joints has been successfully described [21]. The outcome of irradiation does not seem to increase the risk of malignancy [22].

There are few alternative or new treatment options for HO: The long-term effect of bisphosphonates to prevent $\mathrm{HO}$ remains unclear [23]. Basic research found selective retinoic acid receptor $\gamma(\operatorname{RAR} \gamma)$ agonists able to suppress BMP signalling and chondrogenesis in a murine model [24]. Inhibitors of substance $\mathrm{P}$ and mast cell blockers (cromolyn) showed significant reduction in $\mathrm{HO}$ rates in animals and seem to be promising future therapeutics [25]. The use of RNAi might become an additional new alternative [26]. These options are currently at an experimental stage but could become available in the near future to further reduce $\mathrm{HO}$ rates in orthopaedic and trauma surgery.

\section{Conclusion}

This survey indicates that orthopaedic and trauma surgeons in Germany consider $\mathrm{HO}$ to be of clinical relevance in their daily practice. The injuries that are at risk of $\mathrm{HO}$ and require $\mathrm{HO}$ prophylaxis were usually assessed in a 
similar manner. Indications for surgery of symptomatic $\mathrm{HO}$ formations and surgical techniques were equally weighted and are in concordance with the literature. The perioperative oral prophylaxis (i.e. choice of NSAID or COX-2 blocker, application duration) which is often combined with revision surgery was highly variable. This is significant for clinical practice as a long-term use of NSAIDs fosters a potential risk to the patients' safety and could influence the clinical outcome. This survey was able to demonstrate that in 2014 there was still a need for clinical trials as well as national and international treatment guidelines to detect the most effective $\mathrm{HO}$ prophylaxis for risk fractures/injuries and following $\mathrm{HO}$ excision. This could further reduce $\mathrm{HO}$ rates and improve patients' safety in trauma and orthopaedic surgery.

\begin{abstract}
Abbreviations
AC: Acromio-clavicular; BMP: Bone morphogenetic protein; COX: Cyclooxygenase; EndoCert ${ }^{\oplus}$ : A certificate for high standards in THA granted by the German Association of Orthopaedic Surgery; Gy: Gray; HO: Heterotopic ossification; min.: Minimum; max:: Maximum; NSAID: Nonsteroidal anti-inflammatory drug; RAR $\gamma$ : Retinoic acid receptor $\gamma$; RNAi: Ribonucleic acid i; ROM: Range of motion; THA: Total hip arthroplasty.
\end{abstract}

\section{Competing interests}

The authors declare that they have no competing interests.

\section{Authors' contributions}

SW, TR accountable for the conception and execution of the research, the integrity and analysis of the data, and the writing of the manuscript. BeCr, MaWe, FW, HRS, JG, GH accountable for the execution of the research, the integrity and analysis of the data. JM accountable for the integrity and analysis of the data and the writing of the manuscript. All authors read and approved the final manuscript.

\section{Acknowledgements}

The help of Mr. Matthias Munding and Mr. Klaus Bahringer, Department of Orthopaedic Surgery (University of Regensburg, Bad Abbach, Germany) is highly appreciated. The authors would like to thank Mrs. Sophie Hill M.A. (Linguistics) for revising the article.

The authors declare that they had no academic grants or financial support for the current study.

\section{Funding}

No funding was received for this study.

Received: 8 February 2015 Accepted: 8 October 2015

Published online: 22 October 2015

\section{References}

1. Jackson W, Aragon A, Djouad F, Song Y, Koehler S, Nesti L, et al. Mesenchymal progenitor cells derived from traumatized human muscle. J Tissue Eng Regen Med. 2009;3:129-38.

2. Citak M, Suero EM, Backhaus M, Aach M, Godry H, Meindl R, et al. Risk factors for heterotopic ossification in patients with spinal cord injury: a case-control study of 264 patients. Spine. 2012;37:1953-7.

3. Beck A, Salem K, Krischak G, Kinzl L, Bischoff M, Schmelz A. Nonsteroidal anti-inflammatory drugs (NSAIDs) in the perioperative phase in traumatology and orthopedics effects on bone healing. Oper Orthop Traumatol. 2005;17:569-78.

4. Pountos I, Georgouli T, Calori GM, Giannoudis PV. Do nonsteroidal anti-inflammatory drugs affect bone healing? A critical analysis. ScientificWorldJournal. 2012;2012.

5. Ippolito E, Formisano R, Farsetti P, Caterini R, Penta F. Excision for the treatment of periarticular ossification of the knee in patients who have a traumatic brain injury. J Bone Joint Surg Am. 1999;81:783-9.
6. Ashton LA, Bruce W, Goldberg J, Walsh W. Prevention of heterotopic bone formation in high risk patients post-total hip arthroplasty. J Orthop Surg (Hong Kong). 2000;8:53-7.

7. AWMF-German Study Group for the Council for International Organizations of Medical Sciences CIOMS [http://www.awmf.org/]. Accessed August 2015.

8. Balboni TA, Gobezie R, Mamon HJ. Heterotopic ossification: pathophysiology, clinical features, and the role of radiotherapy for prophylaxis. Int J Radiat Oncol Biol Phys. 2006;65:1289-99.

9. Brighton CT, Schaffer JL, Shapiro DB, Tang JJ, Clark CC. Proliferation and macromolecular synthesis by rat calvarial bone cells grown in various oxygen tensions. J Orthop Res. 1991;9:847-54.

10. Alfieri KA, Forsberg JA, Potter BK. Blast injuries and heterotopic ossification. Bone Joint Res. 2012;1:192-7.

11. Visser PS, Krosnick JA, Marquette J, Curtin M. "Mail surveys for election forecasting? An evaluation of the Colombia Dispatch Poll.". Public Opinion Quarterly. 1996;60:181-227.

12. Keeter S, Kennedy C, Dimock M, Best J, Craighill P. Gauging the impact of growing nonresponse on estimates from a national RDD telephone survey. Public Opinion Quarterly. 2006;70:759-79.

13. Moed BR, Maxey JW. The effect of indomethacin on heterotopic ossification following acetabular fracture surgery. J Orthop Trauma. 1993;7:33-8.

14. Griffin SM, Sims SH, Karunakar MA, Seymour R, Haines N. Heterotopic ossification rates after acetabular fracture surgery are unchanged without indomethacin prophylaxis. Clin Orthop Relat Res. 2013.

15. Foruria AM, Augustin S, Morrey BF, Sánchez-Sotelo J. Heterotopic ossification after surgery for fractures and fracture-dislocations involving the proximal aspect of the radius or ulna. J Bone Joint Surg Am. 2013;95:e66.

16. Johansson $\mathrm{T}$, Risto $\mathrm{O}$, Knutsson $\mathrm{A}$, Wahlström $\mathrm{O}$. Heterotopic ossification following internal fixation or arthroplasty for displaced femoral neck fractures: a prospective randomized study. Int Orthop. 2001;25:223-5.

17. Zeckey C, Hildebrand F, Mommsen P, Schumann J, Frink M, Pape H-C, et al. Risk of symptomatic heterotopic ossification following plate osteosynthesis in multiple trauma patients: an analysis in a level-1 trauma centre. Scand J Trauma Resusc Emerg Med. 2009;17:55.

18. Simonsen LL, Sonne-Holm S, Krasheninnikoff M, Engberg AW. Symptomatic heterotopic ossification after very severe traumatic brain injury in 114 patients: incidence and risk factors. Injury. 2007;38:1146-50.

19. Cobb TK, Berry DJ, Wallrichs SL, Ilstrup DM, Morrey BF. Functional outcome of excision of heterotopic ossification after total hip arthroplasty. Clin Orthop Relat Res. 1999;361:131-9.

20. Salazar D, Golz A, Israel H, Marra G. Heterotopic ossification of the elbow treated with surgical resection: risk factors, bony ankylosis, and complications. Clin Orthop Relat Res. 2014.

21. McAuliffe JA, Wolfson AH. Early excision of heterotopic ossification about the elbow followed by radiation therapy. J Bone Joint Surg Am. 1997;79:749-55.

22. Sheybani A, Tennapel MJ, Lack WD, Clerkin P, Hyer DE, Sun W, et al. Risk of radiation-induced malignancy with heterotopic ossification prophylaxis: a case-control analysis. Int J Radiat Oncol Biol Phys. 2014.

23. Vasileiadis GI, Sakellariou VI, Kelekis A, Galanos A, Soucacos PN, Papagelopoulos $\mathrm{PJ}$, et al. Prevention of heterotopic ossification in cases of hypertrophic osteoarthritis submitted to total hip arthroplasty. Etidronate or Indomethacin? J Musculoskelet Neuronal Interact. 2010;10:159-65.

24. Shimono K, Tung W-E, Macolino C, Chi AH-T, Didizian JH, Mundy C, et al. Potent inhibition of heterotopic ossification by nuclear retinoic acid receptor-y agonists. Nat Med. 2011;17:454-60.

25. Salisbury E, Rodenberg E, Sonnet C, Hipp J, Gannon FH, Vadakkan TJ, et al. Sensory nerve induced inflammation contributes to heterotopic ossification. J Cell Biochem. 2011;112:2748-58.

26. Shrivats AR, Hollinger JO. The Delivery and Evaluation of RNAi Therapeutics for Heterotopic Ossification Pathologies. Methods Mol Biol. 2014;1202:14960. doi: 10.1007/7651_2013_34. 